\title{
IAMJ
}

INTERNATIONAL

AYURVEDIC

MEDICAL JOURNAL

ISSN: 2320-5091

Impact Factor: 6.719

\section{AN OPEN-LABEL CLINICAL TRIAL TO PROVE THE EFFICACY OF HIRUDOTHERAPY IN REDUCING THE INCREASED INTRA-OCULAR PRESSURE IN GLAUCOMA}

\section{Jeena N.J.}

Professor \& Head

Dept. Of Salakyathantra (Ophthalmology \& Ent) VPSV Ayurveda College, Kottakkal, Kerala, India

Corresponding Author: drjeenanj@gmail.com

https://doi.org/10.46607/iamj0609072021

(Published Online: July 2021)

Open Access

(C) International Ayurvedic Medical Journal, India 2021

Article Received: 22/06//2021 - Peer Reviewed: 04/07/2021 - Accepted for Publication: 05/07/2021

\section{Check for updates}

\section{ABSTRACT}

Glaucoma is a chronic disease condition prevalent globally leading to blindness. It results in optic neuropathy which is very difficult to manage. An increase in intraocular pressure is a cardinal feature in most cases. This study aims at lowering the intraocular pressure by leech therapy, which is a conventional treatment method described in Ayurveda. Leech therapy was conducted in the selected patients and intraocular pressure before and after treatment were recorded. The study showed clinically and statistically significant changes in the intraocular pressure.

Keywords: Leech therapy, glaucoma, intraocular pressure

\section{INTRODUCTION}

Glaucoma is one of the leading causes of blindness worldwide. It is a group of diseases resulting in optic neuropathy which has got the characteristic changes in the optic nerve head and progressive visual loss. Raised intra- ocular pressure (IOP), optic nerve damage and field defect are the triad of signs seen in glaucoma. A sustained increase in IOP may be due to increased formation of the aqueous humour, blockage in its outflow or a raised pressure in the episcleral veins. The pathogenesis of glaucomatous damage can be attributed to a combination of factors affecting axonal health.

The two main influences are:

(i) mechanical changes due to the rise of intraocular pressure and 
(ii) vascular perfusion of the optic nerve head. Primary open-angle glaucoma is slowly progressing one which causes gradual vision loss whereas angle-closure glaucoma is well known to cause sudden loss of vision. The management of glaucoma ranges from topical medications to surgical interventions as well as laser treatments. Even though many such medical and surgical methods are available, treating glaucoma with protecting vision is still the biggest challenge faced by ophthalmologists. Various randomized controlled clinical trials have shown that lowering intraocular pressure does reduce the progression of primary openangle glaucoma. However, there is a lot of interest in nonpharmacological options that include lifestyle adjustment and alternative and complementary therapy (ACT). Hirudotherapy (HT), the application of medicinal leeches (Hirudinae medicinalis) for therapeutic use, is used by Ayurveda for the treatment of such eye diseases for many centuries. It is considered the safest mode of bloodletting as per Ayurveda and is advised in all age groups without any absolute contraindication. It is seen to give a very quick response in many acute conditions of the eye. The present study was conducted to assess the efficacy of leech therapy in reducing the increased intraocular pressure in patients diagnosed with glaucoma.

\section{MATERIALS AND METHODS}

30 diagnosed patients of chronic open-angle glaucoma (>5 years) in the age group of 40-60 years were included in the present study. Those who had an intraocular pressure of more than

$25 \mathrm{~mm}$ of hg with antiglaucoma medications were selected for a clinical trial. Live healthy leeches of the family Hirudinae medicinalis were used for the treatment. Leech therapy was conducted for 10 sessions over a month in three-day intervals. The site for therapy was around the limbus (ciliary vessels) or inside the palpebrae (palpebral vessels). An indentation tonometer was used to check the intraocular pressure. IOP was measured before and after each therapy session. The values of IOP measured on Day 1, Day 12, Day 21 and Day 30 of Hirudotherapy were taken for analysis. Patients were given ayurvedic eye drops (drops made from Moringa Oleifera) after 30 days and a follow-up IOP was taken at 3 months (Day 90). Difference of IOP of each sitting analysed using paired $t$ test. The difference of IOP between the first sitting and last sitting as well as 3 months follow-up was also analysed using paired t-test.

\section{Day IOP BT IOP AT \% CHANGE}

\section{$133.8 \pm 8.430 .1 \pm 7.7 * 10.1 \%$ \\ $1229.9 \pm 6.926 .7 \pm 5.9 * 10.7 \%$ \\ $2126.2 \pm 5.823 .9 \pm 5.5 * 08.8 \%$ \\ $3023.7 \pm 5.822 .5 \pm 4.605 .1 \%$}

\section{RESULTS}

Patients had a mean age of $49.33 \pm 3.62$ years. There were 21 female and 9 male patients with mean chronicity of $7.33 \pm 1.58$ years. Mean IOP at Day one was $33.8 \pm 8.4$ and after treatment IOP was $30.1 \pm 7.7$ which was statistically significant $(\mathrm{p}<0.05)$ using paired $\mathrm{t}$ test. The results were statistically significant on Day 12 and Day 21 too $(\mathrm{p}<0.05)$. The mean variation from Baseline to Day 30 and follow-up on Day 90 were 32.2 \pm 9.3 , change of $12 \mathrm{~mm}$ of $\mathrm{Hg}$ in IOP which was highly statistically significant using paired t-test $(\mathrm{p}<0.01)$.

\section{Probable mode of action of Leech therapy}

Leech saliva has certain chemical constituents namely hirudin, hyaluronidase and hematine. Hirudin is a thrombin inhibitor and so functions as an anticoagulant. Hyaluronidase is the enzyme that breaks down hyaluronic acid which is a bonding material of connective tissue, and this increases blood flow. The active sucking of blood by the leeches lets out the blood and 
causes a decrease in the pressure of the episcleral ves- the episcleral veins which reduces the intraocular pressels. This in turn increases the aqueous outflow into sure of the eyes.

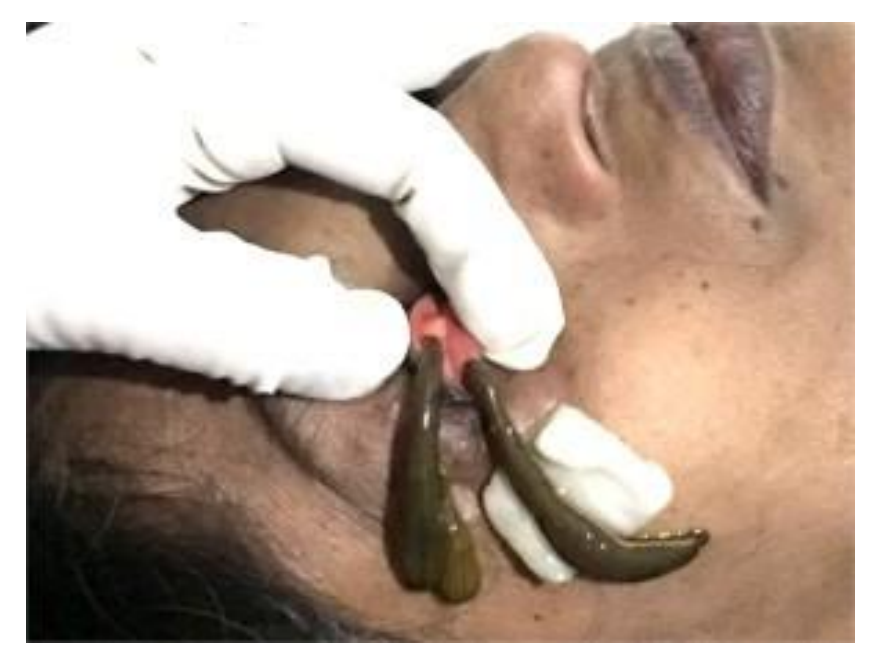

\section{Demographics}

Age 49.33+3.62

Gender Male 09

Female 21

Mean Duration

of Disease $7.33 \pm 1.58$

Antigalucoma Timolol 29

Medication* Latanoprost 13

Brimonidine 04

Dorzolamide 11

The overall change in condition after 1 month

Baseline End of Therapy \% OP IOP change

$32.2 \pm 9.322 .5 \pm 4.6^{*} 30.1 \%$

$*<0.01$

\section{CONCLUSION}

Several well designed randomized controlled trials have demonstrated that lowering the IOP reduces the rate of glaucomatous damage of the optic nerve. The present study looked at the effectiveness of Leech therapy in Chronic Open-Angle Glaucoma in uncontrolled IOP with anti-glaucoma drops. The study showed clinically significant and statistically significant $(\mathrm{P}<0.01)$ changes in immediate reduction and long-term reduction of IOP. Out of all 30 patients, no dropouts were there. The patients had no other complications due to the treatment. The application of leeches (Jalukavacharana) removes not only blood from the body but also injects biologically active substances which help to manage various ailments. The present study indicates the use of Leech therapy as an alternative method for treating Primary Open Angle Glaucoma. Follow up studies will look into continuing efficacy of the therapy in sustaining the IOP, improvement in the Visual field and Neuroprotection. 


\section{REFERENCES}

1. R S Parikh, SR Parikh Alternative therapy in glaucoma management: Is there any role? Indian J Ophthalmol. 2011 Jan; 59(Suppl1): S158-S160.

2. S Abdullah, LM Dar, A Rashid, A Tewari. Hirudotherapy /Leech therapy: Applications and Indications in Surgery Arch Clin Exp Surg. 2012; 1(3): 172-180

3. KERSEY et al: Glaucoma - New Trends in Research Indian J Med Res 137, April 2013, pp 659-66

4. Sujatha Ediriweera: A review on Leech Application (Jalaukavacharana) in Ayurveda and Sri Lankan Traditional MedicineJournal of Ayurveda and Holistic Medicine,2014 Jan;2(Issue1):62-77

5. Parson's Diseases of the eye - Elsevier Publication $20^{\text {th }}$ edition

6. Kenneth C. Churn - Ophthalmology review manual $2^{\text {nd }}$ edition.

\section{Source of Support: Nil}

\section{Conflict of Interest: None Declared}

How to cite this URL: Jeena N.J: An Open-Label Clinical Trial To Prove The Efficacy Of Hirudotherapy In Reducing The Increased Intra-Ocular Pressure In Glaucoma. International Ayurvedic Medical Journal \{online\} 2021 \{cited July 2021\} Available from: http://www.iamj.in/posts/images/upload/1358_1361.pdf 